\title{
Ricardo Donoso
}

\section{Omisiones, errores $y$ tergiversa- ciones de un libro de historia}

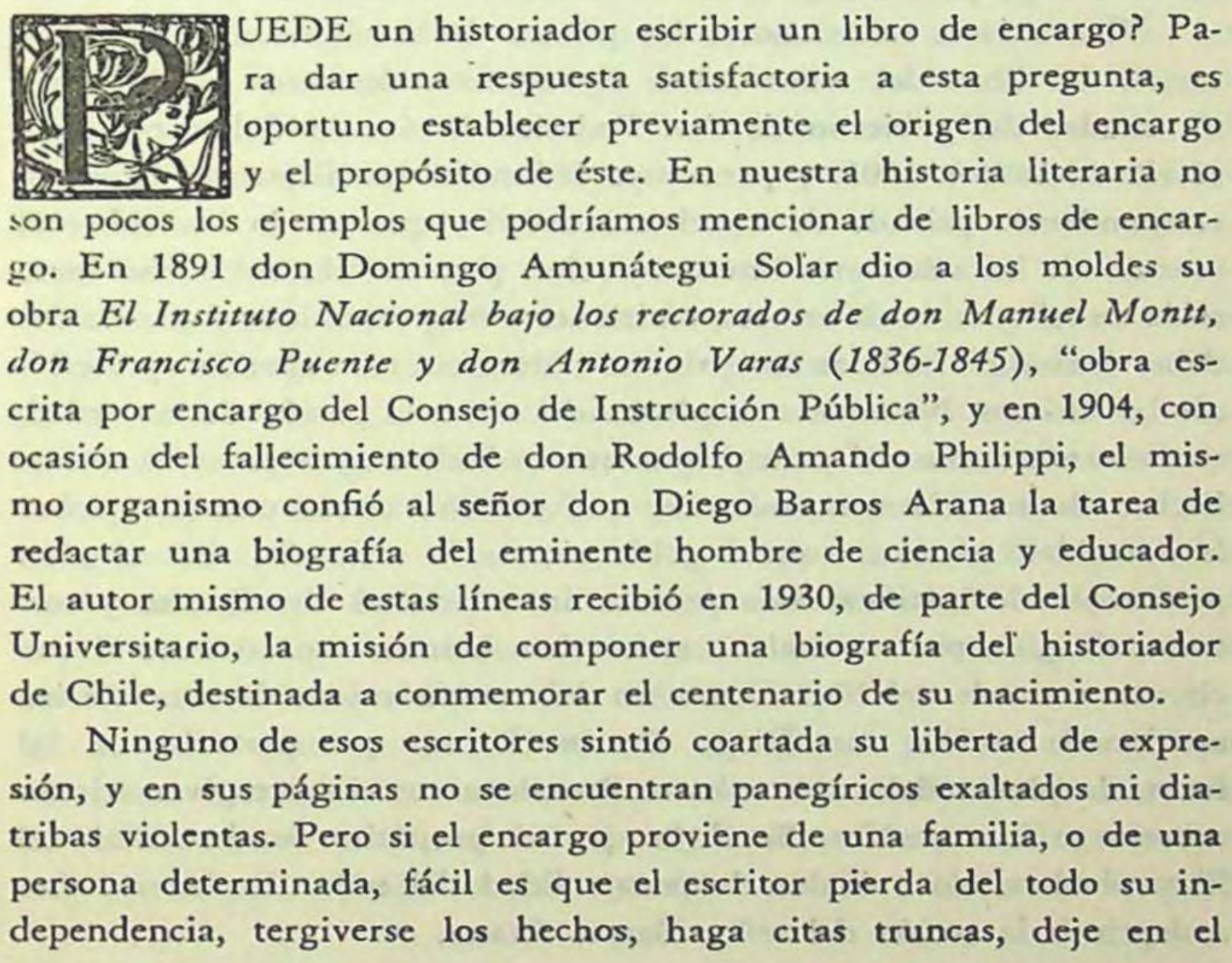


tintero los documentos desfavorables al personaje, y componga una obra tan falsa como tendenciosa. En la historia literaria de los pasados y de los presentes tiempos, podríamos citar muchos ejemplos de obras de esta especie, que estarán frescos en la mente del agudo y docto lector, pero ni aquellos panegiristas pretendieron exhibir el título de historiadores, ni los críticos enterados han dejado de juzgar sus trabajos con severidad, como deleznables frutos de la adulación y el servilismo.

En lo que va corrido del presente siglo no han dejado de crujir las prensas bajo el peso de la composición de tales engendros, pero donde más ha florecido ha sido en la manía genealógica, tan insubstancial como pueril, que satisface la vanidad y el amor propio de incontable número de personas, altamente halagadas con hacer entroncar su estirpe poco menos que con la Casa de Austria.

Vienen estas reflexiones a los puntos de la pluma ante la publicación del libro del señor Jaime Eyzaguirre, destinado a bosquejar un cuadro del gobierno de don Federico Errázuriz Echaurren, que corrió de 1896 a 1901, y para cuya redacción ha dispuesto de la correspondencia privada de aquel mandatario, que arroja luz sobre el manejo de las relaciones internacionales, pero en el cual se ha incurrido en tal cúmulo de errores, omisiones y tergiversaciones, que resulta deber ineludible señalar los primeros, destacar las segundas y rectificar las últimas. No mueve la pluma del autor la pasión de la verdad, sino el entusiasmo del panegirista, que lo inclina a dejar en el tintero hechos de notoria trascendencia, que pesaron como una losa sobre la autoridad moral de aquel gobierno; no lo estimula, sino el afán persistente de justificar una política internacional claudicante y tortuosa, dirigida por un espíritu enfermizo. Una nota persistente sí que circula a través del libro como un leit motiv orientador: la ojeriza apasionada contra don Diego Barros Arana, que perturba en tal forma la pluma del escritor hasta llevarlo a suscribir tergiversaciones notorias e inaceptables. Se diría que el propósito fundamental del libro obedece, no a exaltar la personalidad del señor Errázuriz, sino a deprimir la acción del señor Barros Arana. 
Se abre el libro con una afirmación del todo inexacta, que desde la primera línea descubre la filiación ideológica del autor, y que repudia cuanto proviene de las plumas liberales.

En el estudio del pasado nacional, comienza diciendo, los historiadorcs han puesto como habitual meta de sus trabajos el año 1891, fecha de la gran revolución que trastrocó el régimen político de la República. El resto del siglo XIX y su empalme con la centuria siguiente continúan aún en la zona de los juicios a priori, a pesar de que la perspectiva de más de medio siglo autoriza a afrontar con serenidad su valorización. En efecto, el análisis científico de esa época se impone ya sin demora, no sólo porque un rico acopio documental permite su reconstrucción adecuada, sino también porque, despejando su incógnita, es posible dar con la raíz de las grandes transformaciones experimentadas por Chile en el curso del siglo $\mathrm{XX}$.

Con el intervalo de diez años han visto la luz pública dos trabajos en los cuales se consagran extensas páginas a la administración del señor Errázuriz: uno de don Domingo Amunátegui Solar, La democracia en Chile (1810-1910), dado a los moldes en 1946, y el otro, del autor de estas líneas, que le consagró el capítulo tercero del primer volumen de su obra Alessandri, agitador y demoledor, México, 1952.

Comienza el libro con una introducción panorámica sobre la situación del país hacia 1895 , en la que se dedican dos páginas al territorio y la población, otras dos a la estructura social y tres y media a las tendencias e ideologías, en las que nos encontramos con afirmaciones tan peregrinas como la de que el problema social constituyó una gangrena del siglo XIX. ¿Por qué una gangrena? ¿Acaso no han surgido las cuestiones sociales en todas las épocas de la historia? ¿No sería más exacto decir que en el siglo pasado gravitó el problema social en forma más intensa en los países occidentales, especialmente en el trabajo industrial y en la vida agrícola?

En el capítulo cuarto, destinado al régimen político, no se hace ningún esfuerzo por caracterizar los rasgos sobresalientes de él, como si la libertad electoral y el cohecho no hubieran tenido ninguna trascendencia, para consignar sólo una frase anodina, al decirse que "el 
regimen parlamentario había coincidido con la iniciación de un proceso de crisis en el alma nacional".

¿Crisis de qué? ¿Cuáles eran las expresiones de ella? ¿Por qué no se analizan los factores de todo orden que luchaban por abrir el camino de un mejor standard de vida a las clases medias y desvalidas?

\section{BARROS ARANA}

En las tres páginas dedicadas a la vida cultural, sin tener nada de nuevo, despuntan ya las objeciones del autor a la concepción histórica de Barros Arana, que más adelante veremos acentuadas con las que le merece la acción del hombre público.

Un exponente típico de la idiosincrasia nacional en el campo de la cultura, consigna en la página 32, era la Historia General de Chile, que desde 1884 comenzó a dar a las prensas don Diego Barros Arana, y que hasta 1895 llevaba ya impresos trece volúmenes. Ella se encuadraba en los moldes del más riguroso positivismo, sin pretender elaborar una teoría de las causas que presidieron los hechos históricos, ni remontarse a la menor lucubración de orden filosófico. Por otra parte la configuración mental del señor Barros Arana, ordenada y metódica, pero carente de vuelo especulativo, habría hecho imposible ese intento. No obstante, él aspiró a probar con su obra la efectividad de la ley del progreso indefinido, entonces de moda y la creyó ver demostrada en el tránsito por Chile de la época de dominación española, refractaria a la libertad y la cultura, al período de la independencia y la República, abierta a los goces de la tolerancia y a las luces de la inteligencia que venían de fuera.

En estas catorce líneas el señor Eyzaguirre pretende haber definido el concepto histórico del autor de la Historia General de Chile, para escribir en seguida:

Semejante posición, que por cierto no era exclusiva de Barros Arana, envolvía un repudio a priori de todo el pasado y una postura de desdén frente a las genuinas esencias nacionales.

¿Cuáles serán esas genuinas esencias nacionales? ¿Serán el absolutismo político, el monopolio comercial, la carencia de imprenta y la supremacía de la Iglesia? Sigue diciendo el autor en la misma página: 
Por una singular paradoja, la obra histórica más completa que hasta la fecha se había publicado en el país, y sin parangón en las demás naciones americanas, contribuía más a socavar que a robustecer las raíces de la tradición chilena. Su impulso estaba, por otra parte, en concordancia con la dirección impresa a la enseñanza, desapegada del sentido de la tierra e insaciable en el conocimiento y la admiración de lo extranjero.

Tampoco se puntualiza en qué consistían esas raíces de la tradición chilena. ¿Descansarían ellas en la intolerancia religiosa, en las facultades extraordinarias y los estados de sitio? ¿O deberíamos buscarlas en la difusión de las enfermedades infecciosas, el analfabetismo, en los faroles a parafina y las velas de sebo? $Y$ echándolas de sociólogo, escribe a continuación el autor estas líneas incoherentes:

De espaldas a un pasado que se estimaba vergonzoso y frente a un porvenir cuya determinación provendría de salvadores influjos foráneos, el chileno quedaba así dándose vueltas en un presente sin horizontes, herido por un sentimiento de desconfianza en sus propios valores y buscando en la negación de sí mismo el paso más seguro para seguir adelante. El abandono de grandes objetivos nacionales, como los que otrora inspiraran la vida republicana y la desintegración oportunista y mezquina de la vida política, fucron cosecha inevitable de la orientación impartida sin descanso a través del libro y de la cátedra. Lo que ya se ha dicho acerca del problema en otro sitio del presente trabajo excusa toda insistencia al respecto en este lugar.

Así, tenemos asignada a la responsabilidad de la enseñanza pública el abandono de grandes objetivos nacionales, que no se puntualizan, y la desintegración oportunista y mezquina de la vida política. En esa desintegración ¿̇no le incumbía ninguna parte de responsabilidad ni al egoísmo de las clases dirigentes, ni a los factores económicos, sino a la perturbadora acción desarrollada sin descanso por la enseñanza pública, a través del libro y de la cátedra. Gratuita afirmación, difícil de sostener.

¿Qué nuevas órientaciones surgieron, en los campos social y político, después de Concón y La Placilla? ¿Fue ajeno a esas nuevas orientaciones el Partido Conservador, cuya influencia comenzó a gravitar nuevamente en todos los órdenes de la vida política? El autor guarda un discreto silencio, y el lector queda totalmente ignorante de las consecuencias de aquella catástrofe política que fue la revolución del 91, que sacudió hasta sus raíces a toda la sociedad chilena. 


\section{LA SOMBRA DEL ELECTOR PEÑA}

En el capítulo dedicado a la elección presidencial de 1896, en la que el señor Errázuriz tuvo como competidor a don Vicente Reyes, se anota que el primero pertenecía a la familia "de mayor hábito político de toda la República”, y que reclamaba el poder, no por calculada ambición o necia vanidad, "sino por instinto aristocrático de mando". Más adelante se agrega que su vocación era la política "por imperativo de sangre". El señor Eyzaguirre se ha apropiado, como se ve por las citas anteriores, la fraseología del señor Encina en forma tan absoluta que no da a sus páginas ninguna novedad, sino que las adorna con una fraseología insubstancial.

Pero, en ese capítulo, las omisiones son tan notorias que no escaparán a la atención del agudo lector, ya que están frescas en la conciencia pública las características que tuvo esa elección presidencial, una de las más reñidas y apasionadas de nuestras jornadas cívicas, en la que el cohecho jugó el factor decisivo. Ese instinto aristocrático de mando y ese imperativo de la sangre fueron tal vez los que llevaron al candidato a difundir ese inolvidable retrato con la mano en el bolsillo, harto revelador de que no vacilaría en comprar conciencias para asegurarse el triunfo. Por primera vez en nuestra historia política se llegó al extremo de cohechar electores de Presidente, y por este hecho se podrá comprender los puntos que calzaba el candidato en materia de moralidad política. "Por lo demás gozaba de situación independiente y disponía de una gran fortuna, escribe don Domingo Amunátegui. Había gastado su patrimonio en la candidatura, agrega, pero administraba las valiosas propiedades de la dote de su mujer".

Fresco está el recuerdo de la impresión de indignación que causó tan escandaloso acto de corrupción política, durante una elección estrechísima, que movilizó a todos los elementos cultos de la sociedad chilena, y que tenía valor tan decisivo que determinó finalmente la elección por el Congreso, donde el voto de los parientes aseguró el éxito tan afanosamente buscado. 


\section{LA PUNA DE ATACAMA}

En realidad el interés del libro estriba en las largas páginas consagradas a las relaciones exteriores de Chile con los países limítrofes, para componer las cuales el autor ha dispuesto del archivo personal del Presidente Errázuriz, abierto por primera vez a la curiosidad de un escritor, pero ellas están redactadas con un espíritu tan preconcebido, que no resulta tarea difícil señalar los errores, omisiones y tergiversaciones deliberadas en que se ha incurrido. Al entrar en el capítulo de la historia diplomática surgen de inmediato los prejuicios, que tiñen las páginas del señor Eyzaguirre de apasionamiento e injusticia.

La intervención que en la solución de las cuestiones de límites le cupo al señor Barros Arana, empapa la pluma del autor con tan ciego apasionamiento, que lo lleva a dejar en el tintero los aspectos ingratos de la personalidad cuyo panegírico se pretende bosquejar, y que constan en la documentación misma citada. Las referencias truncas, los fragmentos tergiversados y las omisiones tendenciosas podrán exhibirse en un alegato abogadil, pero jamás en una obra de carácter histórico que aspira a exponer la verdad, con probidad literaria y cruda franqueza.

Con una tenacidad perseverante, que no ha sabido del desalientc, los escritores conservadores han insistido en asignar al señor Barros Arana la responsabilidad de la pérdida de la Patagonia, y en este capítulo el señor Eyzaguirre no hace más que repetir las mismas inexactitudes consignadas por otros historiadores en oportunidades anteriores, pero teniendo buen cuidado de guardar un sepulcral silencio ante cuanto se ha dicho para rebatirlas. No vamos a repetir aquí lo que se argumentó en una polémica resonante, sostenida en la prensa hace más de cinco lustros, de la que no se hace ni la más insignificante mención. Nada parece que halaga más a los escritores conservadores que seguir sosteniendo la responsabilidad ex- 
clusiva del señor Barros Arana en la pérdida de la Patagonia, en circuntancias que al firmarse el tratado de 1881 no tenía ningún cargo de representación popular, ni de responsabilidad política.

El amor propio del señor Barros Arana se veía a la postre satisfecho, consigna el autor en la página 94 con notoria ofuscación. Sólo que esta victoria personal se confundía con la pérdida para la patria de un inmenso territorio, a que por títulos históricos tenía derecho, y que reservaba para el futuro impensadas sorpresas económicas.

Ni el Presidente de la República, ni el gobierno, ni las Cámaras que aprobaron y sancionaron el tratado de 23 de julio de 1881 tienen responsabilidad en ello, sólo ese hombre siniestro y funesto de Barros Arana arrastró al país a ese desastre diplomático y territorial. Es curioso el criterio que mueve la pluma de los escritores conservadores: todos los actos de la vida política y diplomática en que intervienen los hombres públicos conservadores son admirables de acierto, previsión y patriotismo, y están marcados por la estupidez, el derrotismo y la tontería cuanto incumbe a la responsabilidad de los estadistas liberales, y muy especialmente al señor Barros Arana.

Uno de los propósitos fundamentales del libro del señor Eyzaguirre es el de atribuir a la responsabilidad del señor Barros Arana la entrega de la Puna de Atacama. En las páginas 104 y 105 de su trabajo, el autor cita una carta de don Adolfo Guerrero a don Augusto Matte, Ministro de Chile en Francia, de una claridad meridiana sobre el alcance del acuerdo del 17 de abril de 1896, y aludiendo a los comentarios que suscitó en la prensa, recuerda un artículo que publicó don Marcial Martínez en La Nueva República el 12 de mayo de ese año, "en que afirmó sin contradictor y con el reconocimiento privado de don Adolfo Guerrero, que el Protocolo perseguía el traspaso de la Puna a la Argentina por intermedio de Bolivia".

Sin embargo, cinco líneas más abajo, consigna un comentario tan intencionado como injusto cuando dice: 
Los telegramas cambiados entre las autoridades chilenas y argentinas testimoniaron la satisfacción con que en las esferas oficiales de ambos pueblos se recibía la firma del nuevo Protocolo. Y en el reparto de congratulaciones tocó no escasa cuota al perito señor Barros Arana, que sin aparecer ostensiblemente en las negociaciones, las había inspirado a menudo a través del Ministro iniciador de las mismas, don Luis Barros Borgoño, su sobrino, y de su amigo el Canciller Guerrero, que las llevó a definitivo término.

La misma tendenciosa apreciación se repite en la página 223, donde se consigna:

Se dijo en su oportunidad que los principales negociadores de ese Protocolo, los señores Luis Barros Borgoño, Adolfo Guerrero y Diego Barros Arana, habían dado este paso porque consideraban que el título de Chile en la Puna, fundado en la reivindicación, era débil y expuesto al fracaso en un arbitraje...

Y para remachar el clavo, en la página 236 escribe:

Mayor despecho causó aún el arreglo de la Puna a don Diego Barros Arana. Cierto es que él no creía que Chile pudiera invocar título de reivindicación en esa zona; que en 1896 había colaborado activamente con el Canciller Guerrero en la redacción del acuerdo que la traspasaba directamente a la Argentina a través de Bolivia...

El señor Barros Arana, como todos los hombres públicos de la épcca, acogieron el acuerdo del 17 de abril de 1896 como un paso decisivo hacia la solución de la cuestión de límites. En ese intercambio de congratulaciones a que el señor Eyzaguirre alude, ¿no podríamos ver la expresión del vehemente deseo de alejar las amenazas de un conflicto armado y de llegar a una solución por medio del arbitraje? Veamos, entre todas ellas, las cambiadas entre el señor Barros Arana y los señores Uriburu y Mitre. Decían así:

Santiago, 27 de abril de 1896.- Señor Presidente don José de Uriburu.Buenos Aires.

El pacto convenido es un vínculo de paz entre dos naciones que no tienen intereses antagónicos, y que por sus antecedentes y por su cultura están destinadas a ser perpetuamente amigas. La solución de las dificultades de un momento, solución honrosa para ambas, es una prueba más del alto criterio político de V. E., y lo honra como patriota y como hombre de bien.

Reciba las más sinceras felicitaciones de todos los amigos de la paz, así en Chile como en la República Argentina.-Barros Arana. 
Santiago, 27 de abril de 1896.-Señor General don Bartolomé Mitre.Buenos Aires.

Su alcjamiento de la política, su contracción a trabajos de otro orden, y el cansancio consiguiente a una larga vida cmpleada en bien y gloria de la patria, no han impedido a Ud. prestar a la República Argentina y a Chile el inapreciable servicio de afianzar la paz entre ambos países.

Aquí y allá agradecerán a Ud. la participación que ha tenido en estos arreglos. Ellos serán un nuevo motivo para el respeto con que el nombre ilustre de Ud. es repetido a uno y otro lado de los Andes.

Reciba con mis felicitaciones el afectuoso abrazo del vicjo e invariable amigo.-Barros Arana.

Buenos Aires, 27 de abril de 1896.-Señor don Diego Barros Arana.

Fue Ud. el primero que formuló con su pluma magistral de historiador las tradiciones históricas de la unión de Chile y la República Argentina en pro de la emancipación sudamericana.

Hoy le corresponde el honor como hombre de Estado de haber contribuido eficazmente a asegurar la recíproca amistad entre ambos países, poniendo en vía de solución pacífica su cuestión de límites territoriales. Quédale todavía la gloria, que no dudo alcanzará, de llevarla a su feliz terminación, haciéndose acreedor a la gratitud pública de uno y otro lado de los Andes.

Con mis felicitaciones, reciba el afectuoso abrazo de su vicjo amigo que le desea felicidad.-Bartolomé Mitre.

Sin embargo, el autor insiste en asignar la responsabilidad exclusiva del acuerdo al historiador de Chile. Llamemos en primer término la atención al hecho de que ese acuerdo no fue sometido a la aprobación legislativa, y sólo sancionado por un decreto supremo publicado en el Diario Oficial de la República de Chile. El Ministro de Relaciones Exteriores señor Guerrero concurrió al Congreso a explicar sus finalidades y alcance, sin que se alzaran voces, para criticarlo o rebatirlo, de ningún sector de la Cámara, pero ahora surge la pluma del señor Eyzaguirre para echar sobre los hombros del señor Barros Arana la responsabilidad única y exclusiva de su firma.

Pero es extraño que el señor Eyzaguirre, que cita la carta de Guerrero a don Máximo R. Lira, de 12 de abril de 1896, que figura entre los papeles del señor Almirante Latorre, que tuvo a su disposición, no recuerde las palabras de ese documento al respecto:

Después de muchas conferencias con Quirno Costa, se lee allí, y de exploraciones hechas en Buenos Aires por Morla Vicuña, me aventuré a presentar las bases de arreglo, que constan del anexo número 1 . 
Chile cedía por ellas la Puna con el propósito de asegurar el arbitraje y pedía en compensación tierras en el sur.

El gobierno argentino contestó haciendo las proposiciones que van en el anexo número 2 .

No debo ocultarle que esas proposiciones produjeron pésimo efecto en el gobierno. Aceptaban ellos la concesión en la Puna; no nos daban nada en el sur, y todavía se allanan al arbitraje con tales alitrancas y aditamentos que su constitución se hacía imposible.

Por este arreglo la Puna de Atacama queda sometida a arbitraje. ¿Es esto una ventaja para nosotros? No.

Yo como miembro del gobierno, jamás llevaría a un árbitro la cuestión de dominio de la Puna, porque estoy seguro de que el árbitro no lo reconocería como chileno.

Página triste de nuestra historia diplomática, ésa de la entrega de la Puna de Atacama, el señor Eyzaguirre realiza ingentes esfuerzos para librar de su responsabilidad al autor de ella, olvidando deliberadamente cuanto consta de documentos públicos y de los debates del Congreso. La historia es sobradamente conocida, y sacrificados dos años después el Ministro de Chile en Buenos Aires señor Walker Martínez, y el perito don Diego Barros Arana, el señor Errázuriz negoció sigilosamente, a espaldas del Ministro, con el agente confidencial del Presidente Roca, el perito Moreno. Al señor Eyzaguirre le parece una política admirable, digna de elogio, que constituía sólo un golpe de gracia al amor propio del señor Barros Arana. Más valía haber guardado un piadoso silencio, pero tejer panegíricos en torno a actitudes apreciadas en su tiempo con los calificativos más duros, cmpapan de indignación la pluma.

Cuanto el autor ha consignado en la página 237, no puede dejarse pasar sin un comentario.

Esa gota de agua colmaba el vaso de los resentimientos de don Diego hacia don Federico, escribe, que databan de los tiempos de su padre. En efecto, no podía olvidar el señor Barros Arana que el Presidente Errázuriz Zañartu había permitido su salida del rectorado del Instituto Nacional, al que no volvió ni aún después de la ruptura de ese mandatario con los conservadores.

Apuntemos primeramente dos hechos, que el autor olvida deliberadamente. El propio Presidente Errázuriz Zañartu nombró al señor Barros Arana agente diplomático de Chile ante el gobierno de 
Buenos Aires, y el eminente historiador no habría aceptado esa misión de confianza al no mediar el decidido propósito de darle una reparación por el agravio que había recibido. Es cierto que la influencia conservadora ya no pesaba en la Moneda, como también que no habían faltado las explicaciones personales del magistrado al historiador. La parte final de la frase está redactada en forma que puede hacer caer en error al despreocupado lector: el señor. Barros Arana volvió a su cátedra del Instituto Nacional, que él consideraba como su hogar espiritual, apenas regresó de su viaje a Europa, y ya no la abandonó sino unos cuantos meses antes de su muerte.

Pero ni la circunstancia irremediable del triunfo electoral de Errázuriz Echaurren, agrega, ni el hecho de que éste le conservara en su cargo de perito de límites, detuvieron al señor Barros Arana en su crítica. Sardónico e implacable, se solazaba en recordar los tiempos de estudiante de don Federico en el Instituto Nacional, su desaplicación y las argucias de que se valía para sacar adelante sus exámenes. Luego se detenía en contar chascarros sobre la vida nocturna del señor Errázuriz, presentándole como un libertino despreocupado por entero de sus graves deberes de mandatario.

Más le habría valido al autor mantener un discreto silencio sobre las livianas costumbres del magistrado, que no realzaban el prestigio del Presidente de la República, y que el historiador no podía menos de condenar con severidad. ¡Qué tiempos aquellos de la Adelita y de la Pan de Huevo! ¿Cómo no iba a tener el señor Barros Arana, hombre de principios morales y de costumbres austeras, la idea más penosa de ese vividor incorregible que no respetaba siquiera su alta investidura? De aquí que no se mordiera la lengua para aludir a su vida liviana en sus conversaciones y cartas privadas. $Y$ de que no constituían un secreto para nadie sus alegres costumbres, nos ha dejado un testimonio interesante un hombre tan moderado como don Domingo Amunátegui Solar, cuando escribe:

Por desgracia, no llevaba una vida completamente seria, y le agradaba estar rodeado de un grupo de amigos que preferían las costumbres bohemias a los hábitos de trabajo. Este aspecto de su carácter contribuía a desprestigiarle ante el criterio imparcial de las personas de respeto. 
Acordada la entrega de la Puna, se organizó la Junta de Delegados que debía consumar el sacrificio, para lo cual el Presidente Errázuriz obtuvo la cooperación de algunos políticos de alta figuración y destacada personalidad. Tan seguro estaba el Presidente de su acertada política, y de que sus esfuerzos por llegar a un acuerdo pacífico con el país vecino merecerían la gratitud de la nación, que al regreso de los delegados desde Buenos Aires los agasajó con un gran banquete en la Moneda, al cual asistieron las más destacadas personalidades del mundo político y diplomático. Ese banquete, verdadero desafío a las críticas de la oposición, dio el espaldarazo de la aprobación gubernativa a los delegados de la reunión de la capital transandina. Algún tiempo más tarde esos mismos políticos trataron de sacudirse la responsabilidad que pesaba sobre sus hombros, en un memorable debate parlamentario que en la obra del señor Eyzaguirre sólo se recuerda muy de paso.

A este capítulo alude el autor con una desconcertante falta de probidad literaria. En la nota de la página 262, escribe:

Al año siguiente de fallecido el señor Errázuriz, don Diego Barros Arana publicó en La Ley, 22 de enero de 1902, un extenso artículo titulado "La verdad sobre la entrega de la Puna de Atacama", en que afirmó que mientras él luchaba por defender los derechos de Chile en esa región, el Presidente a espaldas suyas y del Plenipotenciario en Buenos Aires, señor Walker, la había entregado. A la defensa del difunto mandatario salió su hijo don Federico Errázuriz Echenique en las columnas de El Ferrocarril, 24 de enero de 1902, exhibiendo abundante documentación que permitía rectificar las afirmaciones del antiguo perito. El señor Barros Arana guardó silencio y no replicó a este artículo.

Efectivamente no contestó ese artículo, pero otros lo hicieron por él. Don Gonzalo Bulnes dejó bien en claro, con coraje cívico que le honra, lo siguiente:

El señor Barros Arana ha comprobado dos hechos que a pesar de todas las injurias que se le han prodigado quedarán como verdades inconcusas para la historia, mientras no se pruebe que el telegrama publicado por él es falsificado. Esos hechos son:

1.0 Que el 18 de julio de 1898 , dos meses antes que se pronunciara la divergencia entre los peritos sobre la línea de frontera, el gobierno ordenó al 
señor Walker Martínez que hiciera un Protocolo con la Cancillería argentina cediéndole la Puna de Atacama.

2. ${ }^{\circ}$ Que en la misma fecha el gobierno ofreció mandar dejar a Buenos Aires, en gloria y majestad, al perito Moreno, a bordo del buque de guerra de nuestra escuadra más simpático por su nombre para la República Argentina.

A continuación, en la misma nota, el autor recuerda el debate suscitado en el Senado en enero de 1902, en el que se discutió la política internacional de don Federico Errázuriz, haciendo citas fragmentarias y dejando en el tintero los puntos fundamentales. Tampoco se dice ni una palabra de la repercusión que ese debate tuvo en la Cámara de Diputados, y que el autor de estas líneas ha recordado en las páginas 66 y 67 del libro ya citado. Lo que dijo don Eduardo Matte en la sesión de 9 de enero está lamentablemente mutilado, lo que estará muy bien en un libro de encargo, pero que en un trabajo de carácter histórico es inaceptable.

Omisiones, errores y tergiversaciones que no hacen honor alguno al autor y que presentan bajo una luz equívoca ese capítulo de nuestra historia diplomática, y que un político de la época llamó "la corona de espinas de la Puna de Atacama".

\section{LA DEFENSA DE CHILE ANTE EL TRIBUNAL ARBITRAL DE LONDRES}

Constituido el Tribunal Arbitral de Londres, el gobierno del señor Errázuriz pidió a don Diego Barros Arana que se trasladara a aquella ciudad a fin de cooperar a los trabajos de la defensa de Chile, por medio de la siguiente carta:

Santiago. 24 de septiembre de 1898.-Señor don Diego Barros Arana.-Presente. - Mi distinguido señor y amigo:

Me es especialmente satisfactorio poner en conocimiento de Ud. que el señor Presidente de la República me acaba de conferir el agradable encargo de expresar a Ud. que el gobierno de Chile tendría viva complacencia en autorizar a Ud. para que, en su carácter de perito, se traslade a Londres, siempre que Ud. estime que su presencia en esa capital habrá de ser necesaria para la mejor defensa de los intereses de Chile ante el árbitro inglés.

Para mí es sobremanera agradable asociarme a este ofrecimiento del señor Presidente y reiterarle, con este motivo, mis felicitaciones y mis agradecimientos 
por el buen éxito obtenido en la parte principal de nuestra contienda de límites y por el valioso concurso con que Ud. ha contribuido a ese buen resultado.

Aprovecho con gusto esta oportunidad para ofrecerle mis consideraciones distinguidas y repetirme su obediente servidor y amigo.-I. J. Latorre.

La contestación del historiador estaba redactada en estos términos:

Somos 24 de septiembre de 1898.-Mi estimado amigo:

En mi propósito de servir en esta cuestión donde pucda ser más útil, no acierto a tomar inmediatamente una resolución sobre el asunto que motiva su carta de hoy. Hágame el favor de expresarle así al señor Presidente, pidiéndole dos o tres días para meditar qué es lo que pueda convenir más a nuestra causa.

Como Ud. comprenderá fácilmente, en mis años la idea de un viaje a Europa no es cuestión que me inquieta mucho; pero si calculo que mi permanencia en Londres ofrece mayor utilidad que lo que pudiera servir aquí, no vacilaría un instante en tomar esta determinación. De todas maneras, el lunes o martes podré dar, según creo, una contestación definitiva.

Me repito, como siempre, su Affmo. amigo y S. S.-Diego Barros Arana.

El historiador terminó por aceptar, se envió el mensaje correspondiente al Senado, donde conservadores y balmacedistas lo torpedearon. De allí a poco, el 12 de noviembre, enterado Barros Arana de los ataques de que se le hacía objeto, en las sesiones secretas de la Cámara de Diputados, por un Ministro de Estado, presentó la renuncia de su cargo. Al día siguiente, 13 de noviembre, escribió el Presidente Errázuriz una carta a don Eulogio Altamirano, reveladora de la odiosidad que había cobrado al ex perito, que el señor Eyzaguirre reproduce con viva complacencia, sobrc todo el párrafo final de la página 241 donde se le califica como el más malo de los chilenos.

En lugar de Barros Arana fue enviado a Londres don Alejandro Bertrand, que había sido el brazo derecho del primero en la Oficina de Límites, y que apenas llegado a la capital británica se encontró en una situación desmedrada, por cuanto no se le cumplía lo que se le había prometido, mientras un nutrido grupo de ociosos se paseaba por Europa con sueldo del Estado. Escribiéndole sobre este particular, a su amigo don Ismael Valdés Vergara, en 8 de febrero de 1899, le decía: 
Si Errázuriz tiene algún resto de rubor no habrá podido menos que subírsele a la cara cuando recibió la carta (u oficio) que le escribió don Domingo Gana por el vapor pasado. La prucba de su hipocresía y su mala conciencia es que no te dijo nada de esto cuando te habló de mí. Y Palacios Zapata siempre tan listo para hacer porquerías.

Los días 8, 9 y 11 de mayo se reunió el Tribunal Arbitral para oir una exposición de los derechos de Chile. Oigamos lo que dice al respecto el autor del libro de encargo:

Entretanto el Ministro de Chile en Londres, don Domingo Gana, asesorado por el ingeniero don Alcjandro Bertrand, trabajó activamente en la defensa de los derechos de Chile ante el Tribunal Arbitral. El extenso memorial que fuc leído ante los jueces en los días 8, 9 y 11 de mayo, desarrollaba ampliamente la tesis chilena de que, en conformidad a los pactos vigentes entre Chile y la Argentina, la línea fronteriza debería pasar por las cumbres más elevadas de los Andes que dividieran las aguas, separando constantemente las vertientes de los ríos que pertenecían a uno y otro Estado y dejando en el territorio de cada país aquellos picos que, por clevados que fueran, no dividiesen las aguas de los sistemas fluviales de los mismos.

\section{Y más adelante agrega:}

Cuando el señor Gana preparaba la redacción del memorial de defensa de los derechos de Chile, fue informado de que don Diego Barros Arana espontáneamente había escrito un trabajo sobre la materia, que le sería remitido para su aprovechamiento. Suspendió sus tareas en espera del nuevo documento, que juzgó de gran utilidad por venir de una pluma tan autorizada como la del ex perito, y al ser recibido incorporó la última parte del mismo, aunque con modificaciones del señor Bertrand, a la memoria que ya tenía hecha.

Es realmente desconcertante que con pluma ligera, en un libro que pretende ser histórico, se tergiverse lo que consta en documentos públicos que corren en letras de molde. El señor Barros Arana había compuesto una Exposición de los derechos de Chile en el litigio de límites sometido al fallo arbitral de $S$. $M$. B., que se publicó en el diario El Ferrocarril en sus ediciones del 5 al 16 de marzo de 1899, obra notable de claridad, de doctrina y de argumentación. El señor Barros Arana envió ese documento, antes de publicarlo, al Ministro de Chile en Londres, y que traducido al inglés, "con muy ligeras modificaciones indicadas por las circunstancias", fue lo que se leyó ante 
el Tribunal Arbitral. El mismo funcionario lo decía al Ministerio, en la nota que envió con fecha 19 de mayo de 1899 , en la que se lee lo siguiente:

Debo manifestar aquí que el trabajo de que nos hemos servido. para ilustrar al Tribunal acerca de los derechos de Chile en esta cuestión, es el que últimamente preparó con tal objeto el señor don Diego Barros Arana y que me remitió antes de darlo en Chile a la publicidad. Con muy ligeras modificaciones aconsejadas por las circunstancias, la exposición del señor Barros Arana, traducida al inglés, ha sido el documento oficial que consigna los hechos, antecedentes y razonamientos sometidos al Tribunal en apoyo al principio fundamental a que obedece el trazado de la línea fronteriza, que el perito de Chile sostuvo en las conferencias de agosto del año pasado y que nuestro gobierno ratificó en las actas de septiembre del mismo año.

Desde que llegó el señor Bertrand a Londres nos habíamos ocupado asiduamente en preparar una exposición análoga, pero los conocimientos especiales del señor Barros Arana en esta materia, el prestigio de su nombre y la calurosa aprobación que su trabajo había hallado en la opinión pública de nuestro país, según hemos visto en las manifestaciones de la prensa, me indujo, en perfecto acuerdo con el señor Bertrand, a dar la preferencia a la exposición del señor Barros Arana, reservando los elementos acumulados por el señor Bertrand para utilizarlos en la réplica, si la hubiere, o en las explicaciones verbales que demandare el Tribunal sobre puntos determinados y concretos (1).

Basta una simple lectura de esa pieza, publicada en la Memoria de Relaciones Exteriores de 1899, y un cotejo con el escrito del eminente historiador y geógrafo, para comprobar que sólo se trata de una traducción al inglés de la Exposición mencionada. Ya podremos deducir los puntos que calza la probidad del escritor ante una tergiversación tan notoria.

Sin embargo, el autor hace mucho caudal del incidente a que dio origen un artículo que publicó el diario La Ley, inspirado por el señor Barros Arana, sobre la base de las informaciones que le proporcionaba el señor Bertrand en su correspondencia privada, en el que se atacaba duramente al gobierno. Ese episodio, sin mayor importancia, pero perfectamente explicable teniendo en cuenta la profunda odiosidad surgida entre el Presidente y el ex perito, agrió aún más los ánimos y cavó entre ellos un abismo profundo.

(1) Memoria del Ministro de Relaciones Exteriores presentada al Congreso Nacional en 1899, tomo_II, páginas 68-69. 
El Presidente, una vez aclaradas las cosas, dio por terminado el incidente, y escribió al señor Gana, como recuerda el autor, que en servicio de la causa de Chile y para su personal conveniencia, pidiera al señor Bertrand se abstuviera de escribir en adelante al señor Barros Arana sobre los negocios de límites. No ocurrió así, sin embargo, y la correspondencia que se conserva nos revela bien a las claras la patriótica dedicación con que el señor Barros Arana siguió cooperando a la defensa de los intereses nacionales.

El Tribunal siguió funcionando y el señor Bertrand haciendo confidencias a su amigo don Ismael Valdés Vergara, en cartas de tan singular importancia que bien merecen salvarse para la historia, pero que el señor Eyzaguirre se ha dejado en el tintero, por cuanto sólo le interesaba exaltar a su personaje y deprimir a Barros Arana.

Mucho te agradezco tu carta del 28 de octubre, le decía el 11 de diciembre de 1899 , y todas las molestias que te ha ocasionado el incidente de las publicaciones, esperando que no se repetirán. Una penosa impresión me queda como a ti, de que una persona a quien quiero, estimo y respeto tanto, como aquella de que se trata, me haya puesto en el caso de aparecer como su antagonista, o mejor dicho, como su denunciador; acaso me acusará de ingratitud, yo no guardo para él ningún rencor, ni quiero ver en lo que ha hecho ninguna mala intención, o por lo menos si la ha habido no se la atribuyo a él. Te aseguro que es una gran satisfacción para mí ver que tú también has creído que la cosa debía sacarse en claro y que has contribuido tanto a obtener ese resultado. Por otra parte, mis relaciones con el Ministro Gana aquí no han sufrido alteración ninguna por estas incidencias, están establecidas sobre la base de la más absoluta franqueza, y así no hemos tenido desde que yo estoy aquí ni un minuto de frialdad ni de desconfianza. Me complazco en repetirte que él se ha impuesto gran trabajo por imponerse bien de la cuestión de límites, y que se consagra con gran dedicación a estudiar todos y cada uno de los puntos que había que tratar.

Y más adelante hay en la misma carta dos párrafos, que el señor Eyzaguirre tuvo buen cuidado de no citar, harto reveladores de la pequeñez de espíritu del Presidente y del curioso criterio de los Ministros conservadores. La cita, aunque larga, merece los honores de la transcripción.

Escrito lo anterior he estado en la Legación, le decía, y don Domingo me ha leído tres cartas del Presidente, todas referentes al asunto de las publicaciones. ¡Vaya que lo han preocupado estos detalles a don Federicol Con una de las cartas le remite a don Domingo una copia de aquélla que por tu conducto envié 
a don Ventura Blanco; ¿crecría acaso don Fcderico que yo le decía aquí cosas distintas a don Domingo de las que le escribía a don Ventura? Dice también que se abstiene de dar opinión sobre esa carta.

IQué modo tan singular de ver los cosas tienen nuestros gobernantes! Parece que todo lo miraran bajo un punto de vista personal y que la tarea principal de todo funcionario fucra de hacérseles agradable. Tú recordarás tal vez que en esa carta yo le hacía al Ministro Blanco un resumen del estado de la cuestión de límites en esa fecha, en términos francos y confidenciales. Me parece que esta clase de datos, provenientes de persona seria, son siempre útiles a un hombre de gobierno, y que lejos de ofenderse si se le habla claro, más bien debe agradecer que no se envuelvan las frases en perifrasis meticulosas. Parece, sin cmbargo, que Blanco no encontró la carta muy de su agrado porque nunca me la contestó, y ahora el Presidente envía acá una copia de ella, como una cosa escrita por $\mathrm{mi}$ a escondidas. Se ha tomado un trabajo inútil porque las mismas opiniones que expreso en esa carta muchas veces me las había oído el Ministro Gana en conversación.

Y como era hombre de carácter y estaba resuelto a mantener sus opiniones, le agregaba que preferiría cualquier cosa antes de obrar contra su conciencia. De la correspondencia cambiada entre los señores Bertrand y Valdés Vergara, el señor Eyzaguirre, siguiendo su invariable propósito de dejar en el tintero las partes ingratas a la defensa de los intereses de Chile, que puedan deslucir la alta capacidad del gobierno de Santiago que él le supone, cita sólo algunos fragmentos. Así de la carta de 4 de marzo de 1901, que reproduce en la página 343, incluye sólo un párrafo, el menos interesante, por cuanto en ella se hacen comentarios acerbos a la labor del "experimentado diplomático" don Máximo R. Lira. Mucho más interesante es aún la carta que el mismo señor Bertrand dirigió a su amigo de Santiago el 23 de agosto de 1901, en la que con hondo desconsuelo de patriota dejaba constancia del pobre apoyo recibido de parte del Ministerio de Relaciones Exteriores, del candor de un diplomático chileno que intervino en la negociación de 1896, y de la notoria ineptitud del perito don Arístides Martínez, sucesor de Barros Arana. Por último, en la carta de 29 de noviembre del mismo año hay algunas referencias a los signos de postración moral que por entonces surgían en el país, que bien pudo recoger un historiador honesto, interesado en bosquejar los rasgos esenciales de la situación porque atravesaba, en un momento histórico de su desenvolvimiento. 
En el mismo capítulo hay una apreciación del fallo arbitral harto insuficiente y reveladora de precario estudio. En la página 344 escribe el autor:

Descartando tanto la línea divisoria de las aguas como la de las más altas cumbres, el Tribunal inglés se atuvo en el fallo más bien a la posesión y procuró distribuir equitativamente los terrenos que eran objeto de litigio.

Veamos lo que escribe el distinguido geógrafo Dr. Hans Steffen, que cooperó a la defensa de los intereses de Chile ante el Tribunal de Londres, sobre ese fallo, para ver cuál de las doctrinas encontró mejor acogida.

Por un lado, el informe del Tribunal Arbitral, por cuyas declaraciones Holdich es evidentemente el principal responsable, afirma que "un límite orográfico puede ser indeterminado si cada una de las cumbres por donde pasa no está claramente especificada, en tanto que una línca hidrográfica, desde el momento que se indican las hoyas, permite su demarcación en el terreno". Con esto, el Tribunal reconoce sin duda alguna la superioridad teórica de la línea propuesta por Barros Arana sobre la vaga e indeterminada proposición del perito argentino. Por otra parte, el trazado definitivo del límite en la Patagonia se desvía prácticamente tanto de la línea divisoria de las aguas que, en lugar de seguir una norma fija, o sea, una condición geográfica que prescriben los Tratados, su curso parece ser determinado por razones arbitrarias y completamente ajenas a las disposiciones de aquéllos.

Se podría creer que los perjuicios sufridos por Chile a causa de la arbitraria demarcación realizada por el Tribunal inglés en la sección norte de la zona litigiosa de la Patagonia, hubiesen sido recompensados hasta cierto punto por el hecho de que la línea de Barros Arana fue aceptada como frontera definitiva en la región que sigue un poco más al sur. Pero si se examina la línea arbitral de esta sección en sus detalles, se ve pronto que presenta desventajas considerables para Chile y aun interrumpe en partes la continuidad de su territorio.

Si bien es cierto que el Tribunal inglés ha trazado, agrega más adelante, en la comarca de que tratamos, una frontera que, según las declaraciones oficiales del perito argentino, habría sido para él inaceptable y aun indiscutible, esta derrota fundamental de los principios mantenidos por los representantes argentinos en la demarcación, se atenúa considerablemente por varias razones.

Obra de elemental justicia habría sido la de destacar la importancia de la alta cuestión de doctrina geográfica que estaba en el tapete de la discusión, la trascendencia del pronunciamiento del Tribunal Arbitral, y la fundamental y decisiva cooperación del señor 
Barros Arana a la defensa de los intereses territoriales de Chile. Sobre todo ello se guarda un deliberado silencio.

(CONCLUIRA).

Hallándose en prensa estas páginas, el señor don Horacio Walker Larraín ha hecho circular un folleto que lleva por título La cuestión de límites con Argentina durante la Administración Errázuriz Echaurren (Editorial del Pacífico S. A.), en el que se hacen al señor Eyzaguirre los mismos reparos que formula el autor de estas páginas, en el sentido de que se trata de una obra apologética y no de una obra histórica. El señor Walker Larraín recoge especialmente lo relacionado con la misión diplomática de su ilustre padre ante el gobierno de Buenos Aires, y escribe:

"Con todo, cuando se recorren las páginas de su nuevo libro, el lector se forma el juicio de estar frente a un apologista y no ante un historiador".

"En vista de este antecedente, agrega en la página 10, ¿es justo, es serio, es honrado, el prurito de un escritor, que en otras ocasiones quiso y pudo escribir historia, de presentar en su libro a un diplomático que representó a Chile ante cinco naciones y ante dos Congresos Panamericanos, con aplauso de los diversos gobiernos que lo acreditaron, como empeñado en buscar a todo trance una guerra fratricida?"

Y más adelante, aludiendo a las citas truncas de documentos en que incurre el señor Eyzaguirre, se pregunta:

"¿Es lícito para un escritor compulsar sólo partes de un documento, salvo cuando así se altera el pensamiento del firmante, como ocurre en este caso?" Refiriéndose al asunto de la Puna de Atacama, el señor Walker Larraín escribe en las páginas 17 y 18 de su folleto:

"Es importante para la finalidad que persigue este folleto puntualizar que los ataques al señor Walker de parte del Presidente de la República o de alguno de sus secuaces, en los que se le señalaba como un guerrero a todo trance, no nacieron durante las incidencias recordadas, ni se fundaron en sus actuaciones ante el gobierno argentino, aprobadas todas por el nuestro, como lo comprueban los propios documentos insertos en el libro en referencia. Surgieron tales ataques sólo cuando el señor Walker se negó a secundar la acción personal del Presidente Errázuriz en el asunto que la prensa y la opinión pública llamaron "la entrega de la Puna de Atacama".

El memorándum que publica el señor Walker Larraín, inédito hasta ahora, constituye una pieza lapidaria para juzgar al Presidente Errázuriz Echaurren y su responsabilidad histórica en el manejo de las relaciones exteriores del país, que comenta con estas palabras, coincidentes en un todo con lo consignado en las páginas anteriores:

"Al señor Eyzaguirre no ofrece el menor reparo el proceder del Presidente de la República, que gestionó un arreglo de tanta importancia con otro país, sin informar una palabra siquiera a nuestro Ministro en Buenos Aires, ni al perito don Diego Barros Arana, ni a su propio Ministro de Relaciones Exteriores". 